\title{
Examining the Efficacy of a Novel Augmented Reality Mobile Delivery Platform for the Enhancement of Asthma Care Education for Children
}

\author{
https://doi.org/10.3991/ijim.v15i07.20379 \\ Suha Al-Naimi $\left({ }^{凶}\right)$ \\ University of Suffolk, Ipswich, UK \\ s.al-naimi@uos.ac.uk \\ Peter Brady and Thomas Andrews \\ Orbital Media, Stowmarket, UK \\ Chris Janes and Fandi Ibrahim \\ University of Suffolk, Ipswich, UK \\ Mohamed Abdel-Maguid \\ Canterbury Christ Church University, Kent, UK
}

\begin{abstract}
MySpira is the world first augmented reality (AR) asthma inhaler training app; it enables children to learn asthma keywords, types of inhalers, the preparation of the inhaler and spacer, asthma triggers, and develop skills on how to use an asthma inhaler effectively. All of these are compiled into an enjoyable 20-minute experience, introducing likable characters and tactile interactions, which incentivise the child to progress all the way through the learning experience. This study aimed to compare the efficacy of the MySpira application to traditional educational material (e.g. leaflets and videos) to improve asthma treatment compliance, technique and user engagement amongst 110 schoolchildren, aged 6 to 13. The findings indicate that MySpira surpasses the traditional educational materials, specifically in terms of enjoyment rating, the use of different inhalers' techniques, particularly in the younger group (aged 6-9 years). Therefore, MySpira may enhance the level of available asthma care in an attempt to resolve one of the major problems facing asthma suffers and their carers, notably effective use of asthma inhalers.
\end{abstract}

Keywords-Augmented reality (AR), MySpira, Asthma, Care Education for Children

\section{$1 \quad$ Introduction}

Asthma affects 5.4 million people in the UK, of which 1.1 million are children [1]. It remains one of the leading causes for paediatric hospital admissions and has a prevalence rate of approximately $10 \%$ in children leading to missed days from school and 
other societal costs. Asthma costs the NHS up to $£ 1.1$ billion yearly treating the condition via emergency admissions, GP appointments, medicines and other resources [2]. Inhaled drugs are the primary treatment for asthma, and incorrect handling of inhalers and inappropriate inhaler technique result in low bronchial deposition of the drug and can contribute to poor asthma management [3]. Various studies have shown that many asthma sufferers use their inhalers incorrectly in one way or another, which can result in less than $10 \%$ of the medicine reaching where it is needed in the lungs [4]. This is concerning since Vestbo et al. reported in an observational study nested within a randomised controlled trial that adherence to inhaled medication was associated with a significantly reduced risk of death and admission to hospital due to Chronic Obstructive Pulmonary Disease (COPD) exacerbations [5]. Retrospective analyses of COPD large patient and medication databases have also identified that increased proportion of days covered with inhaler medications is associated with reduced hospital and emergency presentations for COPD patients [6], [7]. Where proper inhaler training programmes have been put in place, emergency admissions have reduced by $50 \%$ and asthma associated deaths by $75 \%$ [8].

In an effort to reduce the impact of serious and fatal asthma attacks on children, and with the recent advances in mobile Augmented Reality (AR) technology, the popularity of applications such as Pokémon Go [9] and the growing recognition of $\mathrm{AR}$ as an effective educational platform [10], [11], a novel mobile app, MySpira, was developed for the purpose of educating children how to improve inhaler technique in a unique and an engaging way [12]. MySpira was developed as an approach to supplement existing asthma care educational materials and utilises AR and gamification to improve engagement. MySpira, takes the user through seven learning experiences, each designed to be engaging and fun to play through. In each of the stages it enables children to learn asthma keywords, types of inhalers, the preparation of the inhaler and spacer, asthma triggers, and develop skills on how to use an asthma inhaler effectively [12]. All of these are compiled into an enjoyable 20-minute experience, introducing likable characters and tactile interactions, which incentivises the child to progress all the way through to the end of the learning experience.

This study is an information recall study to evaluate the effectiveness of the new AR app MySpira in comparisons with the existing asthma education leaflets and videos in the education of children aged between 6 and 13 on causes of asthma, which inhalers to use and how to use them. The hypothesis is that gamification enhances engagement in educational programmes and thus increase correct inhaler technique and efficacy.

\section{$2 \quad$ Materials and Methods}

\subsection{Development of MySpira}

The concept of improving correct inhaler usage involves changing the asthmatic's behaviour. Game design is an integral part of this behavioural change. From the very beginning of development, the team needed to understand the target audience and 
create ways to engage and motivate young players on a deeper emotional level compared to watching a video or reading a leaflet. MySpira achieves this through novelty, challenge and meaning to create an emergent experience. Games are a set of activity loops which create emotion and it is that emotion or the anticipation of the emotion which drives behaviour and behavioural change [13].

MySpira was designed with Nicole Lazzaro's “4 Keys 2 Fun” which is a set of core emotions and outcomes that captivate gameplay [14], [15]. MySpira implements easy fun in the way of controlling the screen with AR functionality and with a fantasy world from which the characters derive. Easy fun isn't part of the main goal, but they are a set of interactions that engages curiosity to hook the player into the moment. "It entices the player to consider options and find out more" [14]. These types of experiences keep the player engaged and immersed.

Hard fun is implemented in the use of clear goals such as placing letters in the correct place, preparing the virtual inhaler and inhaling the virtual medicine via MySpira. Challenge is important to keep the player motivated. The player can become compelled to move forward if the player is kept within the flow state between skill level and challenge. Too much challenge will create anxiety and lack of challenge will create boredom. "Games intentionally restrict and frustrate the player to develop the skills" [13]. When this happens, it creates a sense of winning and encouragement to invest time in what they are doing, vital for player motivation and willingness to invest more time to progress further.

In MySpira, once the user has completed a learning module or been taught a subject, the game rewards them with badges and collectables with a strong visual stimulation via colours and particle effects. This is a common way of implementing serious fun and is a way of enhancing the win feeling. It is used in MySpira at crucial moments to provide a way of learning difficult asthma subjects and to improve information recall.

The team were able to provide an experience that goes beyond the level of engagement that videos and leaflets offer. "In a game, anytime you take an action, you receive instant feedback. Positive feedback reinforces good behaviour, strategy and tactics, while negative feedback enables you to learn quickly and adjust" [16].

\subsection{Study participants}

In this study, we recruited 110 children by working with local schools in Suffolk and using their facilities to collect data (Figure 1). Written parental consent was obtained from each child participated in the study after a full explanation of the purpose and nature of all procedures used and ethical approval for the study was obtained from the University of Suffolk Advisory Committee on Ethics.

The children were aged between 6 to 13 years old and were not suffering from asthma during the time of the investigation. They were stratified into two age groups (6-9 and 10-13 years old) based on the schooling level, and within each school, the participants were randomized upon admittance into the three educational materials i.e. leaflet, video and MySpira. The educational content of each learning material was sourced from the NHS, Asthma UK and other asthma online resources (Table 1). The 
leaflets were easy to read, included imagery and were aimed at children. The video was a combination of videos found on NHS sites and Asthma UK, available to all ages. Both the videos and leaflets included the same information contained in MySpira.

Each participant completed a multiple-choice questionnaire (Appendix 1) before receiving the asthma material (leaflet, video or MySpira). This assessed the child's knowledge of asthma, the triggers that induce asthma, the different types of asthma inhalers and how best to use them. The children do not have asthma so their knowledge was anticipated to be low. The children where then given 20 minutes to read the leaflets, 25 minutes to watch the videao and 25 minutes to play the App. On completion of the exercise the children where then asked to complete the questionnaire again.

The variables assessed based on the questionnaire were overall educational experience score (OVEAS), the inhaler procedure (based on response to questions 2, 9, 10, $11,12,14,15,16,19,20$ and 21), differentiating the inhaler type (based on response to questions $2,4,6,22,23,26$ ), differentiating the inhaler techniques (based on questions 17 and 21), and the enjoyment rate (based on response to questions 13 or 27).

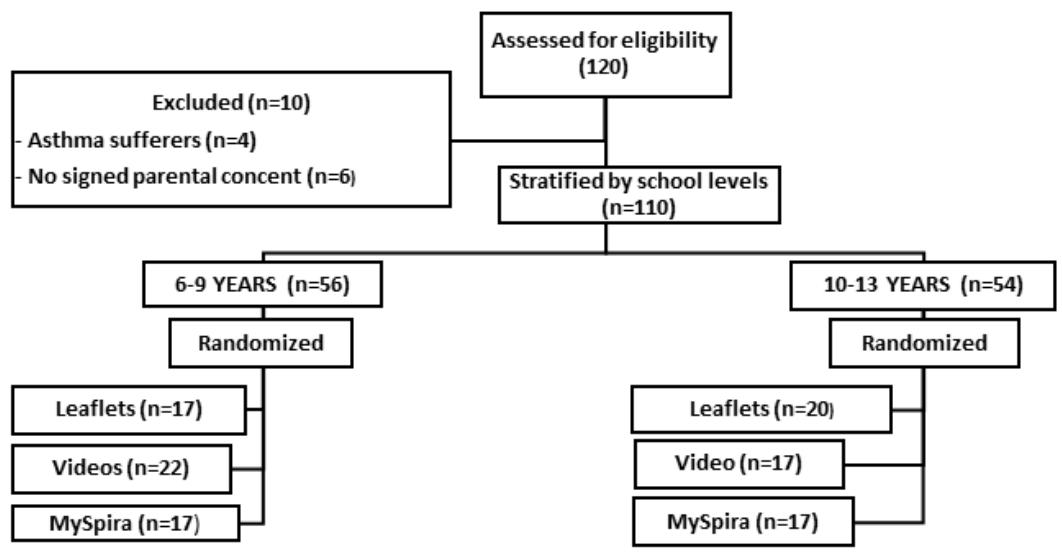

Fig. 1. The baseline characteristics of the participants and their stratification across the various educational materials 
Table 1. Resources provide to each group.

\begin{tabular}{|c|c|}
\hline $\begin{array}{c}\text { Randomised } \\
\text { group }\end{array}$ & Material provided \\
\hline Leaflets & $\begin{array}{l}\text { All about asthma. (2015). [pdf] London: Asthma UK. Available at: } \\
\text { https://www.asthma.org.uk/globalassets/health-advice/resources/easy- } \\
\text { read/easy_read all_about_asthma booklet.pdf [Accessed 1 Jun. 2018]. } \\
\text { NHS Corby. (n.d.). [online] Available at: http://www.corbyccg.nhs.uk/inhaler- } \\
\text { techniques-leaflets/ [Accessed 1 Jun. 2018]. } \\
\text { What is Asthma. (n.d.). [pdf] Easy Health. Available at: } \\
\text { http://www.easyhealth.org.uk/sites/default/files/null/What\%20is\%20asthma\%3F.pdf } \\
\text { [Accessed 1 Jun. 2018]. }\end{array}$ \\
\hline Videos & 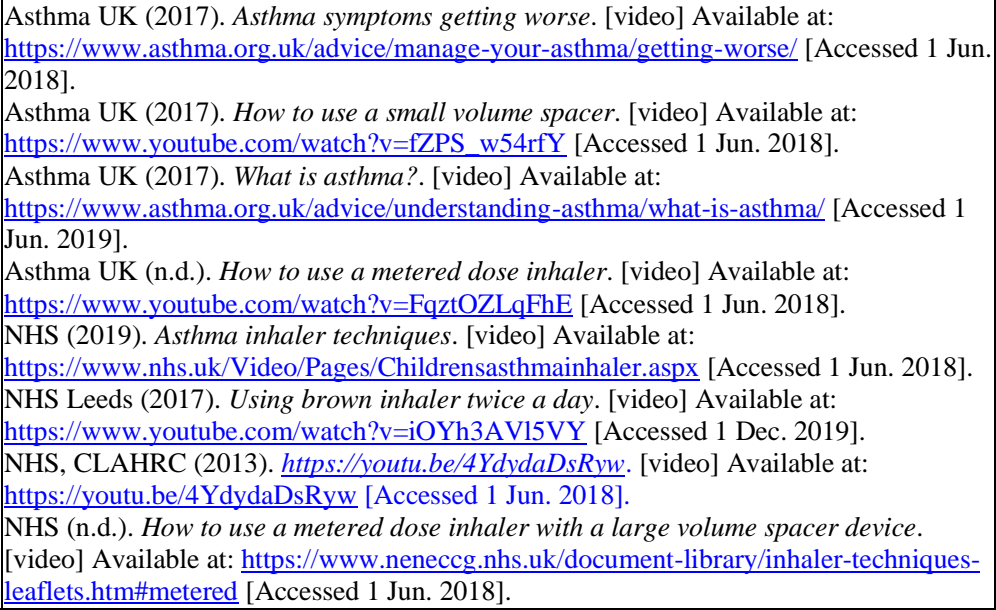 \\
\hline MySpira App & $\begin{array}{l}\text { Apple AppStore - https://apps.apple.com/gb/app/myspira/id1316936001 } \\
\text { Google Play Store - } \\
\text { https://play.google.com/store/apps/details?id=com.OrbitalMedia.MySpira }\end{array}$ \\
\hline
\end{tabular}

\subsection{Statistical analyses}

The changes from the baseline (results from first questionnaire) were compared among the educational material groups (MySpira, Leaflet, and Video) using the multivariate techniques within the General Linear Model in SPSS and employing Tukey HSD as the multiple comparison test. The assumption of normality and the homogeneity of variances were verified with graphical analysis of the residual plots. All statistical analyses were performed using Statistical Package for the Social Sciences (SPSS) version 20.0 (SPSS, Chicago, Illinois, USA).

\section{Results}

The finding indicates that the mean changes in the overall education experience score (OVEAS) showed significant increase across the learning materials but no significant interactions (Figure 2a). MySpira tends to have the largest change from the baseline (3.48 vs 2.74 and 2.05 for the video and leaflet, respectively). On the other hand, examining each age group (Figure 2 b,c), MySpira significantly outperformed 
the leaflet but not the video in the 6-9 years old group only ( $\mathrm{p}=.0 .032$ and 0.538 , respectively).

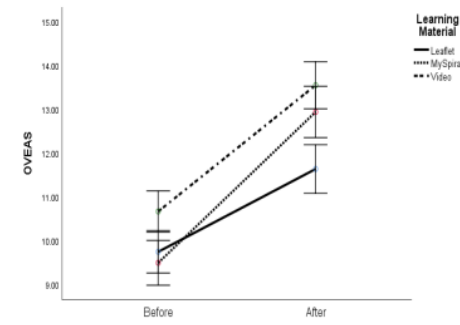

a) all participants $(n=110)$

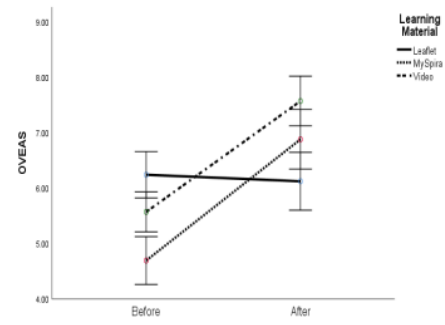

b) age group 6-9 $(\mathrm{n}=56)$

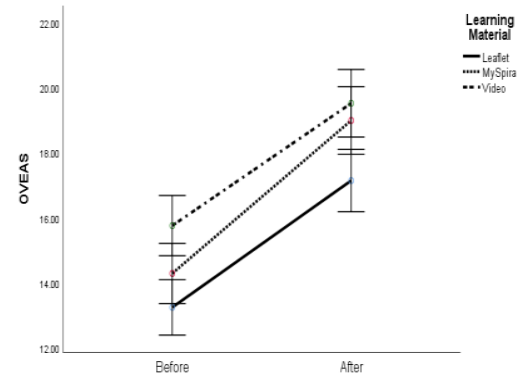

c) age group 10-13 $(\mathrm{n}=54)$. The values represent mean $( \pm \mathrm{SE})$.

Fig. 2. The changes in the overall education experience score (OVEAS) over the course of the study

Overall, the inhaler procedure increased significantly for MySpira and video group but not for the leaflet group (Figure 3a). MySpira has the largest change from the baseline and significantly outperformed the leaflet but not the video $(\mathrm{p}=0.037$ and $\mathrm{p}=0.957$, respectively). Examining the age groups, MySpira outperformed the leaflet but no the video $(\mathrm{p}=0.032$ and $\mathrm{p}=0.538$, respectively) in the 6-9 years age group (Figure 3b), while there is no significant change from the baseline in MySpira compared to either the leaflet or the video in the 10-13 years age group ( $\mathrm{p}=0.441$ and $\mathrm{p}=0.629$, respectively) (Figure 3c). 


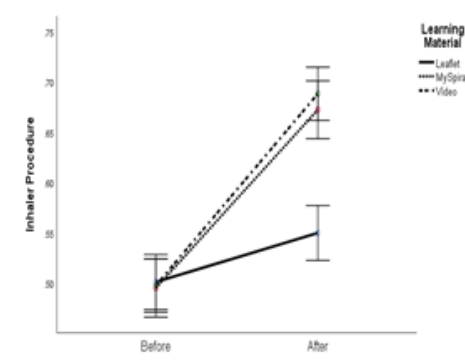

a) All participants $(\mathrm{n}=110)$

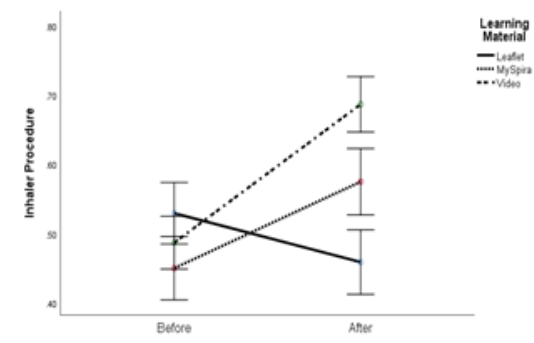

b) Age group 6-9 $(\mathrm{n}=56)$

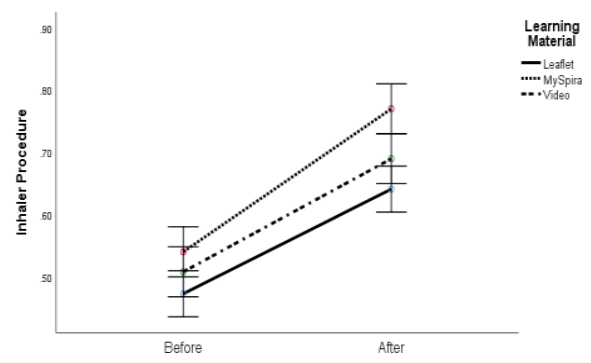

c) Age group 10-13 $(\mathrm{n}=54)$. The values represent mean $( \pm \mathrm{SE})$.

Fig. 3. The changes in the Inhaler Procedure over the course of the study

The overall changes in differentiating the inhaler types showed a significant increase was shown in MySpira and video but not in the leaflet (Figure 4a); however, the changes from the baseline for MySpira was not significantly higher in compared to the leaflet or the video ( $\mathrm{p}=.0119$ and 0.968 , respectively). For the 6-9 year age group, MySpira outperformed the leaflet but not the video $(\mathrm{p}=0.014$ and $\mathrm{p}=742$, respectively) (Figure 4b). For the 10-13 year age group, no significant changes were observed within or between groups (Figure 4c). Meanwhile, the mean changes in Differentiating the Inhalers' Techniques over the course of the study for all participants at age group 10-13 outperformed the leaflet and video $(\mathrm{p}=0.0001$ and $\mathrm{p}=0.001$, respectively, Figure 5). 


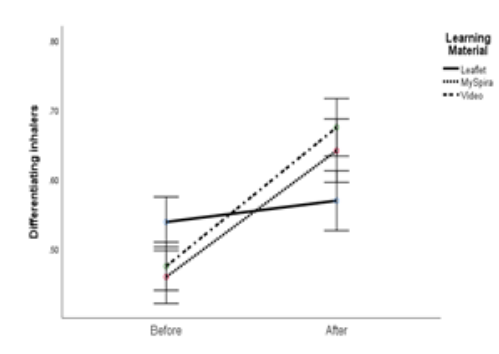

a) All participants $(\mathrm{n}=110)$

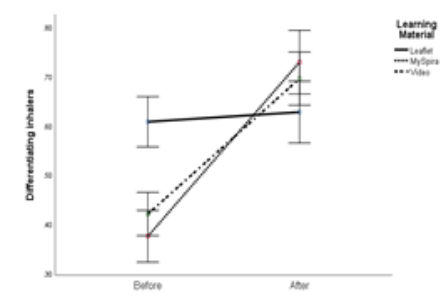

b) Age group 6-9 (n=56),

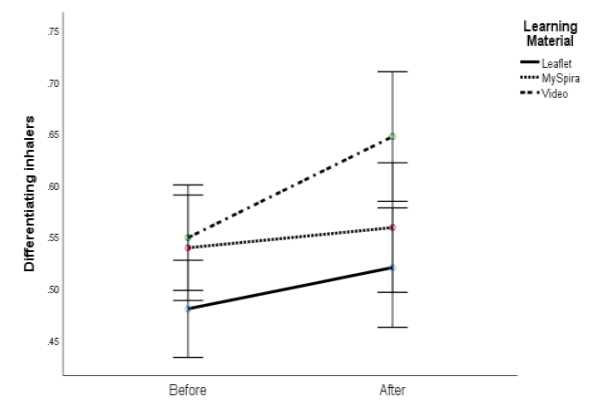

c) Age group 10-13 $(\mathrm{n}=54)$. The values represent mean $( \pm \mathrm{SE})$

Fig. 4. The changes in Differentiating the Inhalers' types over the course of the study

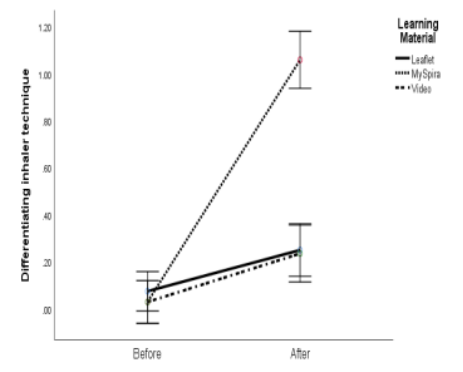

Fig. 5. The Differentiating the Inhalers' Techniques over the course of the study for all participants at age group 10-13 $(n=54)$. Only MySpira group has seen changed from the baseline and significantly outperformed the leaflet and video $(p=0.0001$ and $p=0.001$, respectively). 
The Enjoyment Rates of the learning materials showed that MySpira significantly outperformed the leaflet and video learning materials $(\mathrm{p}=0.017$ and 0.038 , respectively) (Figure 6a). In the younger age group (6-9 years), MySpira showed significant enjoyment rate compared to leaflet $(0.003)$ but not compared to the video $(\mathrm{p}=0.128)$. No significant differences were observed in the 10-13 year age group (Figure 6b).

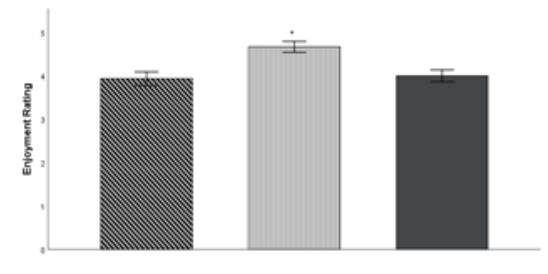

a) All participants $(\mathrm{n}=110)$

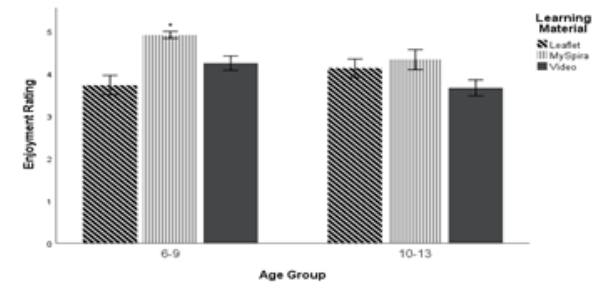

b) For age group 6-9 $(\mathrm{n}=56)$ and age group 10-13 $(\mathrm{n}=54)$.

Fig. 6. The Enjoyment Rates of the Learning Materials. The values represent mean $( \pm \mathrm{SE})$.

\section{Discussion}

This study is an information recall study examining the knowledge about asthma in 110 non-asthmatic schoolchildren age range between 6 and 13 years old. The study managed to explore whether augmented reality training games called 'MySpira' can improve the knowledge on asthma compared to traditional asthma education methods (e.g. leaflets and videos). We found that MySpira performs better than the other educational materials but outstandingly outperforms the other materials in enjoyment rating and the use of the different inhalers' techniques. This positive result for the emerging technology suggests that this type of learning would have great benefits for children with asthma. Using proper inhaler techniques give a better outcome for asthma sufferers [17], showing that basic education may provide teachable moments to address poor proficiency, especially for younger children. The Samady et al. study found that nearly half of 113 hospitalised asthmatic children age 2-16 years demonstrated improper inhaler use, meaning the patients were not taking in the full dose of medication [17].

Previously, computer-based education that have been used to tackle asthma in children has not shown promising results. For example, Homer et al. evaluated the effectiveness of an interactive educational computer programme for children aged 3 to 12 years in a trial involving 137 subjects, and during the 12-month follow-up period, no differences in health care use, symptoms, or functional status were observed beyond some increase in asthma knowledge in the treatment group children [18] [19]. In a trial with 438 children divided into traditional asthma education and computer assist- 
ed asthma education, Runge et al. found no differences in efficacy between the interventions [20]. In this study however, MySpira managed to take the children in a 20minute journey teaching them about; asthma keywords, types of inhalers, the preparation of the inhaler and spacer, asthma triggers, and how to use an asthma inhaler effectively [12]. This is evident by the fact that MySpira significantly overtook the other learning materials in the enjoyment rates despite MySpira did not only show significant changes in the knowledge rate gained by the children. Interestingly, the age group 6- 9 years benefited most from the App compared to the older age group. An association between learning and enjoyment is an everlasting philosophy, and recent studies in both the US and England suggest that the lack of enjoyment is one of the underpinning explanations for children and young adults failing to achieve their potential [21], [22], [23] . Unfortunately, self-management asthma education is still inadequately provided [24], [25]. This can be explained by many factors, including patient-related barriers to participation in such programmes, physicians' nonintegration of asthma education into current practice, and/or structural and organisational problems. Simpler educational interventions have previously been proposed but many have failed to improve asthma control, although most could reduce exacerbations [26], [27]. A study in 2015 was conducted by Plaza et al. suggests that "simplified" educational interventions can be effective if they offer the essential elements of an effective educational intervention [28] such as key information on asthma management and inhaler technique training [29]. Consequently, MySpira was developed and used in our study as an approach to supplement existing asthma care educational materials and utilises augmented reality (AR) and gamification to improve user engagement [12].

\section{Conclusion}

The findings indicate that gamification and augmented reality techniques outperform traditional educational methods such as leaflets or videos specifically in terms of enjoyment, learning outcomes and the use of different inhalers' techniques, particularly in the children aged 6-9 years. However, there is a need to evaluate the efficacy of MySpira in enhancing patient outcomes (Asthma suffers) as a consequence of improved engagement and knowledge retention.

\section{References}

[1] Asthma UK, (2017). Affects 5.4 million people in the UK, 1.1 million of whom are children https://www.asthma.org.uk/about/media/facts-and-statistics/

[2] DoH, UK, (2017) https://www.england.nhs.uk/wp-content/uploads/2017/03/NEXTSTEPS-ON-THE-NHS-FIVE-YEAR-FORWARD-VIEW.pdf https://doi.org/10.18411/a$\underline{2017-023}$

[3] Roy A, Battle K, Lurslurchachai L, Halm EA, Wisnivesky JP. Inhaler device, administration technique, and adherence to inhaled corticosteroids in patients with asthma. Prim Care Respir J. (2011). 20(2):148-54. https://doi.org/10.4104/pcrj.2011.00022 
[4] Molimard M, Raherison C, Lignot S, Depont F, Abouelfath A, Moore N, et al. Assessment of handling of inhaler devices in real life: an observational study in 3811 patients in primary care. J Aerosol Med. (2003). 16(3):249- 54 https://doi.org/10.1089/089426803769017 $\underline{613}$

[5] Vestbo J, Hurd SS, Agusti AG, et al (2013). Global strategy for the diagnosis, management and prevention of chronic obstructive pulmonary disease, GOLD executive summary. Am J Respir Crit Care Med: 187(4): 347-365. https://doi.org/10.1164/rccm.2012040596PP

[6] Simoni-Wastila L, Wei Y-J, Qian J, et al. (2012). Association of chronic obstructive pulmonary disease maintenance medication adherence with all-cause hospitalization and spending in a medicare population. Am J Geriatr Pharmacother 10(3): 201-210. https://doi.org/10.1016/j.amjopharm.2012.04.002

[7] Toy EL, Beaulieu NU, McHale JM, et al. (2011). Treatment of COPD: relationships between daily dosing frequency, adherence, resource use, and costs. Respir Med; 105(3): 435-441. https://doi.org/10.1016/j.rmed.2010.09.006

[8] NICE, UK, (2018). Monitoring asthma control https://www.nice.org.uk/guidance/ng80/ chapter/Recommendations\#monitoring-asthma-control

[9] SurveyMonkey: Pokémon GO is now the biggest mobile game in U.S. history, https:// www.cnbc.com/2016/07/13/pokemon-go-now-the-biggest-mobile-game-in-us-history.html

[10] Dunleavy, M., Dede, C., Mitchell, R., (2009). Affordances and limitations of immersive participatory augmented reality simulations for teaching and learning J. Sci. Educ. Technol. 18, 7-22. https://doi.org/10.1007/s10956-008-9119-1

[11] Wu, H.K., Lee, S.W.Y., Chang, H.Y., Liang, J.C. (2013). Current status, opportunities and challenges of augmented reality in education. Comput. Educ. 62, 41-49. doi:10.1016/j.compedu.2012.10.024. https://doi.org/10.1016/j.compedu.2012.10.024

[12] Janes C, Andrews T and Abdel-Maguid M. Designing an Augmented Reality Smartphone Application for the Enhancement of Asthma Care Education. (2018). (AISC volume 725). https://doi.org/10.1007/978-3-319-75175-7__2

[13] Lazzaro, N. Nicole Lazzaro (2013). Games and the Four Keys to Fun: Using Emotions to Create Engaging Design. [podcast] Head, Heart, Hand: AIGA Design Conference. Available at: https://www.youtube.com/watch?v=EEmNRRRqgNc [Accessed 26 Sep. 2019].

[14] Lazzaro, N. (2004) Why We Play Games: Four Keys to More Emotion Without Story. [ebook] XEODesign, ${ }^{\circledR}$ Inc. Available at: http://www.xeodesign.com [Accessed 26 Sep. 2019].

[15] Manikanthan S.V, Padmapriya T, Azham Hussain, Thamizharasi E., (2020) Artificial Intelligence Techniques for Enhancing Smartphone Application Development on Mobile Computing. iJIM - Vol. 14, No. 17. https://doi.org/10.3991/ijim.v15i01.17437 https://doi. org/10.3991/ijim.v14i17.16569

[16] Horn, T. (2013). An Overview of Gamification. [online] Gamasutra. Available at: https://www.gamastra.com/blogs/ToddHorn/20130529/193230/An Overview of Gamific ationphp [Accessed 26 Sep. 2019].

[17] Samady W, Rodriguez VA, Gupta R, Palac H, Karamanis M, Press VG., (2019). Critical Errors in Inhaler Technique among Children Hospitalized with Asthma. J Hosp Med. 1;14(6):361-365. https://doi.org/10.12788/jhm.3195

[18] Homer C, Susskind O, Alpert HR, et al. (2000). An evaluation of an innovative multimedia educational software program for asthma management: report of a randomized, controlled trial. Pediatrics; 106 (1 Pt 2):210-5.

[19] Drigas A., Kokkalia G., (2016). Mobile Learning for Special Preschool Education. iJIM Volume 10, Issue 1. https://doi.org/10.3991/ijim.v10i1.5288 
[20] Runge, C., et al. (2006). Outcomes of a web-based patient education program for asthmatic children and adolescents. Chest. 129(3). https://doi.org/10.1378/chest.129.3.581

[21] Goetz, T., Nathan C., Hall, B., Anne, C., Frenzel, A., \& Pekrun, R., (2006). A hierarchical conceptualization of enjoyment in students. Learning and Instruction, 16, 323-338. https://doi.org/10.1016/j.learninstruc.2006.07.004

[22] Shernoff, D.J., Csikszentmihalyi, M., Schneider, B., \& Shernoff, E.S., (2003). Student engagement in high school classrooms from the perspective of flow theory. School Psychology Quarterly, 18(2), 158-176. https://doi.org/10.1521/scpq.18.2.158.21860

[23] Amin K A., Sudana I., Setyosari P., Djatmika E T., (2021). The Effectiveness of Mobile Blended Problem Based Learning on Mathematical Problem Solving. iJIM - Vol. 15, No. 01. https://doi.org/10.3991/ijim.v15i01.17437

[24] Boulet LP, Devlin H, O'Donnell DE., (2011). The Physicians' Practice Assessment Questionnaire on asthma and COPD. Respir Med; 105: 8-14. https://doi.org/10.1016/j.rmed. $\underline{2010.07 .022}$

[25] Boulet LP, Bourbeau J, Skomro R, et al. (2013). Major care gaps in asthma, sleep and chronic obstructive pulmonary disease: a road map for knowledge translation. Can Respir J; 20: 265-269. https://doi.org/10.1155/2013/496923

[26] Dalcin PT, Grutcki DM, Laporte PP, et al. (2011). Impact of a short-term educational intervention on adherence to asthma treatment and on asthma control. J Bras Pneumol; 37: 19-27. https://doi.org/10.1590/S1806-37132011000100005

[27] Morell F, Ojanguren I, Cordovilla R, et al. (2014). Two short interventions to reduce health care requirements in asthma patients. A multicentre controlled study (ASTHMACAP II). Med Clinica; 142: 348-354. https://doi.org/10.1016/j.medcli.2013.01. $\underline{051}$

[28] Plaza V, Peiró M, Torrejón M, et al. (2015). A repeated short educational intervention improves asthma control and quality of life. Eur Respir J; 46: 1298-1307. https://doi.org/10. 1183/13993003.00458-2015

[29] Gardner A, Kaplan B, Brown W, et al. (2015). National standards for asthma selfmanagement education. Ann Allergy Asthma Immunol; 114: 178-186. https://doi.org/10. $\underline{1016 / j . a n a i .2014 .12 .014}$

\section{Acknowledgement}

The authors are grateful to all the children who helped and participated in this project. MySpira was developed by a transdisciplinary team from the School of Engineering, Art, Science and Technology at the University of Suffolk and Orbital Media. The work was partially supported by the UK government, through the Innovate UK Knowledge Transfer Partnership funding programme: KTP010440.

\section{Authors}

Dr Suha Al-Naimi (corresponding author), is the Principal Investigator for the project and the course leader for the BSc (Hons) Nutrition and Human Health programme at the University of Suffolk. A qualified professional in the fields Chemical Pathology and Metabolic Medicine. With a broad-based experience in both national 
and international environments, she is an Executive Editor for the areas of Nutrition and Metabolism for the Journal of Physiology and Biochemistry (JPBY).

Peter Brady is the CEO of the Orbital Global and founder of Orbital Media. The Orbital Global is referred as "the world leading digital experts". Moreover, the Orbital Media is one of the UK's most innovative Digital Media Agency's, recently winning a coveted award for Most Innovative Global OTC Campaign.

Thomas Andrews is a Game Developer \& Programmer at the Orbital Media, UK. He leads a number of projects which utilise immersive technologies such as AR and VR to educate users on a specific topic. His time at Orbital Media began as part of a Knowledge Transfer Partnership between Orbital and the University of Suffolk.

Dr Fandi Ibrahim is an Associate Professor at the University of Suffolk. He is an internationally recognised expert in the field of functional foods. He worked as a Researcher at the Functional Food Forum, University of Turku, Finland, and also worked as a scientist in DuPont Nutrition and Health, Finland. He was involved in this study to estimated the required sample size and carried out the statistical analysis.

Dr Chris Jane is the course leader for Computer Games Programming at the University of Suffolk, Prior to joining the University, Chris was a gameplay programmer who worked on a range of educational and serious games. He is best known for being programmer and project lead of Hidden: Source, a modification of Half-Life 2, which has won numerous awards and was a finalist at the Independent Games Festival awards in 2006. He contributed to the study design.

Professor Abdel-Maguid, is the Pro Vice-Chancellor (STEM) and Dean of the Faculty of Science, Engineering, and Social Sciences at the Canterbury Christ Church University, UK. He is responsible for leading the development of the Institution's Transdisciplinary STEM agenda, bringing together a broad range of STEM, nearSTEM and non-STEM disciplines to create one transdisciplinary innovation environment. Moreover, he was the Dean of the School of Engineering, Arts, Science and Technology at the University of Suffolk. He was responsible for leading the University's STEM research, business engagement and innovation strategies where he was at the forefront of a number of regional initiatives, securing more than $£ 15 \mathrm{~m}$ of external funding.

Article submitted 2020-12-08. Resubmitted 2021-01-13. Final acceptance 2021-01-15. Final version published as submitted by the authors. 


\section{$9 \quad$ Appendix 1}

\section{Asthma Quiz 6-9 A}

Learning Material:

Age:

ID:

School:

(1.) What causes the symptoms of Asthma?

Mark only one oval.
Medicine
Triggers
Choking
Inhalers

(2.) What is the most common colour for the relieverinhaler?

Mark only one oval.

$\bigcirc$ Green

$\bigcirc$ Brown

$\longrightarrow$ Pink

Blue

(3.) How many seconds do you hold your breath for after inhaling the medicine? Mark only one oval.
C 10
5
15
30

(4.) Which Inhaler is used for fast treatment?

Mark only one oval.
Combination
Reliever
Preventer
Dry-powdered 
Paper-Examining the Efficacy of a Novel Augmented Reality Mobile Delivery Platform for the..

(5.) When should you carry your inhaler?

Mark only one oval.

At home

At school

Always

When playing

(6.) What is the most common colour for the preventerinhaler? Mark only one oval.

$\square_{\text {Gold }}$ Blue
$\square_{\text {Groen }}$

(7.) Which of these is NOT an asthma trigger? Mark only one oval.

$\longrightarrow$ Pollution

Exercise

Pollen

Coughing

(8.) Which of these is NOT an Asthma symptom? Mark only one oval.
Coughing
Pollution
Wheezing
Shortness of breath

(9.) How should you inhale the medicine? Mark only one oval.

Through your nose

Sharply

Slowly and deeply

Quickly 
Paper-Examining the Efficacy of a Novel Augmented Reality Mobile Delivery Platform for the...

(10.) How should you position your head while inhaling? Mark only one oval.
Upright and normal
With your head back
Downwards and normal
Forward and normal

(11.) What position is recommended when using yourinhaler?

Mark only one oval.

Lying on the back

Standing or sitting

Lying on the chest

Curled forward

(12.) How long should you wait in between 'puffs'? Mark only one oval.

$30-60$ seconds

5-10 seconds

1-3 seconds

1-2 minutes

(13.) How much did you enjoy the learning material?

Not very much 1 


\section{Asthma Quiz 10-13 A}

Learning Material:

Age:

ID:

School:

(1.) What causes the symptoms of Asthma? Mark only one oval.

$\square$ Medicine
Triggers
Choking
Inhalers

(2.) What is the most common colour for the relieverinhaler? Mark only one oval.
$\bigcirc$ Green
Brown
Pink
Blue

(3.) How many seconds do you hold your breath for after inhaling the medicine? Mark only one oval.

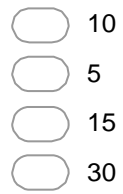

(4.) Which Inhaler is used for fast treatment? Mark only one oval.

Combination

Reliever

Preventer

Dry-powdered 
Paper-Examining the Efficacy of a Novel Augmented Reality Mobile Delivery Platform for the...

(5.) When should you carry your inhaler?

Mark only one oval.

$\square$ At home
At school
Always
When playing

(6.) What is the most common colour for the preventer inhaler? Mark only one oval.
$\bigcirc$ Blue
Gold
Brown
Green

(7.) Which of these is NOT an asthma trigger? Mark only one oval.

$D_{\text {Pollution }}$ Exercise
$D_{\text {Pollen }}$
Coughing

(8.) Which of these is NOT an Asthma symptom? Mark only one oval.
Coughing
Pollution
Wheezing
Shortness of breath

(9.) How should you inhale the medicine?

Mark only one oval.
Through your nose
Sharply
Slowly and deeply
Quickly 
Paper-Examining the Efficacy of a Novel Augmented Reality Mobile Delivery Platform for the...

(10.) How should you position your head while inhaling? Mark only one oval.
Upright and normal
With your head back
Downwards and normal
Forward and normal

(11.) What position is recommended when using your inhaler? Mark only one oval.
Lying on the back
Standing or sitting
Lying on thechest
Curled forward

12.) How long should you wait in between 'puffs'? Mark only one oval.
$30-60$ seconds
5-10 seconds
1-3 seconds
1-2 minutes

(13.) Tick all of the asthma triggers Check all that apply.
Pollen
Sleeping
$\square$ Pollution
Wheezing
$\square$ Coughing
Dust
Exercise

(14.) What should you do before inhaling the medicine? Mark only one oval.

Hold your breath for 5 seconds

Shake the inhaler

Inhale 6 times

Put your name on the inhaler 
(15.) Should your teeth be between the mouth piece? Mark only one oval.

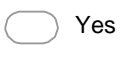

No

(16.) How many puffs should someone take on their inhaler per dose? Mark only one oval.

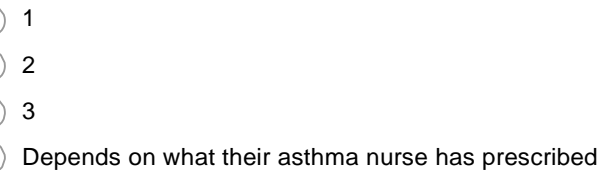

(17.) Tick all of the methods that can be used to inhale the medicine. Check all that apply.
Multi-breathe method
Fast-breathe method
Single-breathe method
Slow-breathe method

(18.) Do you need to use a spacer for the multi-breathe method?

Mark only one oval.

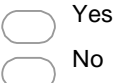

(19.) Why do you need to breathe out fully before breathing in the medicine? Mark only one oval.

So that the medicine is ready

To make room for the medicine to go

So that you get oxygen to your brain

To clear any blockages

(20.) What part of the inhaler should you remove? Mark only one oval.

The medicine

The colour

The plastic casing

The cap 
(21.) If using the multi-breathe method of inhaling. How many deep breaths should you take?

Mark only one oval.

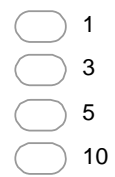

(22.) The preventer inhaler works best when used over a short period of time?

Mark only one oval.

True

False

(23.) What is a preventer inhaler good at? Mark only one oval.

Reducing the inflammation around the area of the airways.

Loosening the muscle bands.

Tightening the muscle bands.

Increasing the inflammation around the area of the airways.

(24.) A spacer is used because...

Mark only one oval.

it's lightweight and easy to hold.

It makes it easier to get the right amount of medicine to the lungs and reduces the risks of side effects.

it speeds up the time it takes to breathe in the medicine.

$\bigcirc$ it can tell you how to inhale the medicine.

(25.) The tubes in a person's lungs who is suffering from asthma are narrow because... Mark only one oval.

The muscle bands become tight and the area around the airways becomes inflamed.

The muscle bands become loose and breathing starts to get difficult.

There is not enough oxygen.

The muscle bands become swollen. 
Paper-Examining the Efficacy of a Novel Augmented Reality Mobile Delivery Platform for the..

(26.) What is one of the positive effects of using a reliever inhaler? Mark only one oval.

It reduces the inflammation around the area of the airways.

It loosens the muscle bands.

It tightens the muscle bands to make you stronger at breathing.

It increases the inflammation in the lungs.

(27.) How much did you enjoy the learning material?

Not very much 1 